\title{
Optimization of electronic devices placement on printed circuit board
}

by M. Felczak, T.Wajman and B. Więcek

Technical University of Łódź, Wólczańska 211/215, 90-924 Łódź, Poland

\begin{abstract}
Power densities generated in today's electronic components arise very quickly. Optimal placement of the devices on the board plays very important role for dissipation of power to the ambience. Each electronic component, as a heat source, thermally interacts with other ones. Forced convection is still one of the most important ways of heat dissipating from electronic components. When fluid moves along the board, the components placed upstream have better cooling conditions than the ones placed downstream. It happens because moving fluid warms up. This phenomenon is called thermal wake effect [7-10].

The paper consists of two parts. The aim of the first part is to increase heat transfer from electronic devices and reduce negative results of thermal wake effect. It is possible by increasing turbulence intensity. There were performed simulations and measurements of electronic devices with extra elements improving heat transfer. They have various shapes and dimensions.

Second part includes optimization of electronic devices placement on printed circuit board. Devices are placed along a bottom surface of a duct and cooled with forced convection by air stream with velocity v. Optimization method includes genetic algorithm as an engine searching near optimal placement of electronic devices and thermal solver which calculates temperature distribution in two dimensions. Optimization was carried out in a view of thermal criteria.
\end{abstract}

\section{Devices enhancing heat transfear - numerical simulations}

Three dimensional simulations of two electronic components (size $0.03 \times 0.03 \mathrm{~m}$ ) and the PCB were performed in Fluent software (Fig. 1a). The distance between heat sources equals to $0.02 \mathrm{~m}$. Adiabatic boundary conditions are applied for the bottom of the PCB edges. Printed circuit board is assumed to be made with weakly thermally conducting material.

Air moving along the board warms up. It makes that module $\mathrm{P}_{2}$ has larger temperature than $P_{1}$. In case to reduce negative results of this phenomenon there are performed three dimensional simulations of electronic devices with extra elements enhancing heat transfer (Fig. 1b-d). Heat sources temperature distributions are presented in a Fig. 2. For each case both sources are assumed to generate the same power.

There is a function $\theta$ describing thermal wake phenomenon $\left(\theta=\frac{T_{2}-T_{a}}{T_{1}-T_{a}}\right)$,

(where $T_{1}$ - upstream heat source, $T_{2}$ - downstream heat source, $T_{a}$ - ambient temperature) [8], which is calculated for all the configurations of the devices enhancing heat transfer. The lower function is the smaller differences in both devices cooling conditions are. For $\theta=1$ both of the heat sources have the same temperature. 


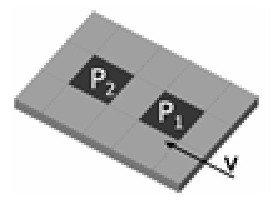

a)

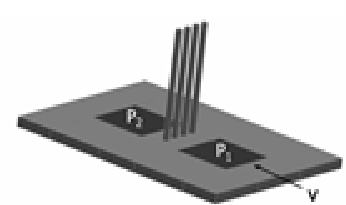

b)

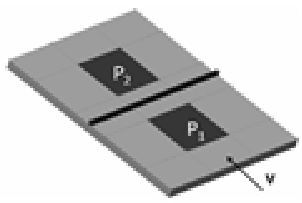

c)

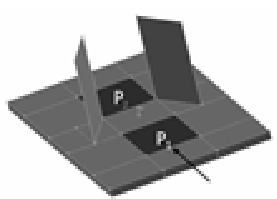

d)

Fig. 1. Configurations of the devices enhancing heat transfer: a) heat sources with no extra devices, b)vertical pins introducing turbulences, c) bar with square cross-section $0.001 \mathrm{~m} \times 0.001 \mathrm{~m}$ height, d) heat sources with no extra devices, d) air speed accelerator

For the heat sources with no extra devices enhancing heat transfer (Fig. 1a) thermal wake function $\theta$ linearly grows with rise of the cooling air speed (Fig. 3a). For the configuration b) and c) the dependency between $\theta$ and velocity is nonlinear. It is due to the fact that for the case with no extra devices heat sources are cooled with forced laminar convection, while for the rest cases all the extra devices introduce turbulences, what makes $\theta$ changes nonlinear versus air velocity.

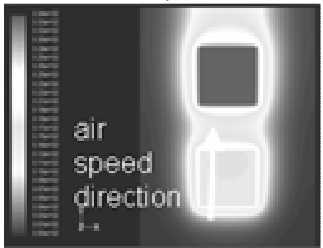

a)

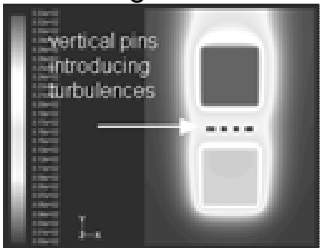

b)

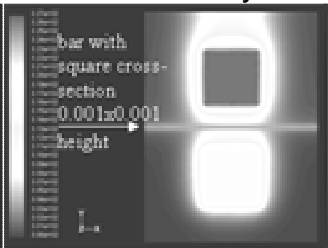

c)

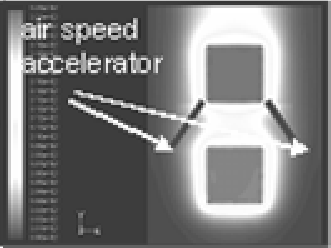

d)

Fig 2: Temperature distribution for the cooling configurations presented in a Fig. 1: a) heat sources with no extra devices, b)vertical pins introducing turbulences, c) bar with square cross-section $0.001 \times 0.001$ height, d) air speed accelerator

In configuration d) thermal wake function value is almost independent on air speed velocity in the range $1-3 \mathrm{~m} / \mathrm{s}$. All the numerical simulations were performed in Fluent software. Both heat sources generate the same power equal to $1.125 \mathrm{~W}$.

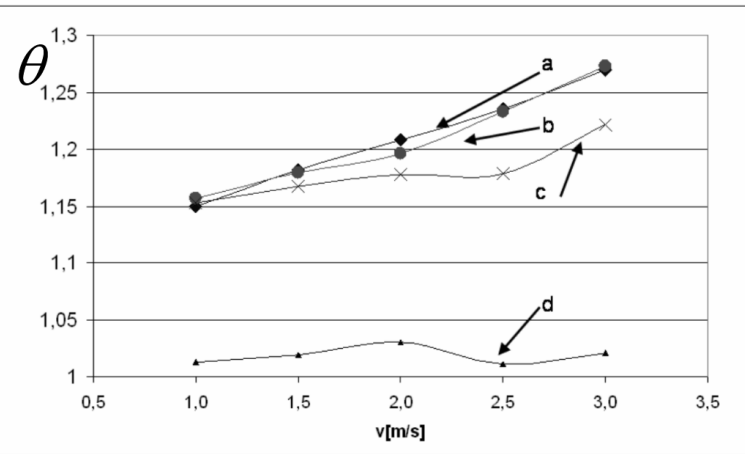

Fig. 3. Thermal wake function versus air speed velocity (numerical simulations) 
Dependency between $T_{2}-T_{a}$ and $T_{1}-T_{a}$ in a function of air velocity is presented for all cooling configurations (Fig. 4). The higher difference between the function values are, the larger disproportions between both devices cooling conditions are.

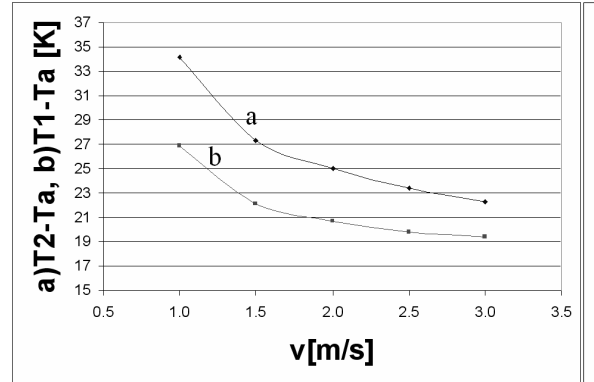

a)

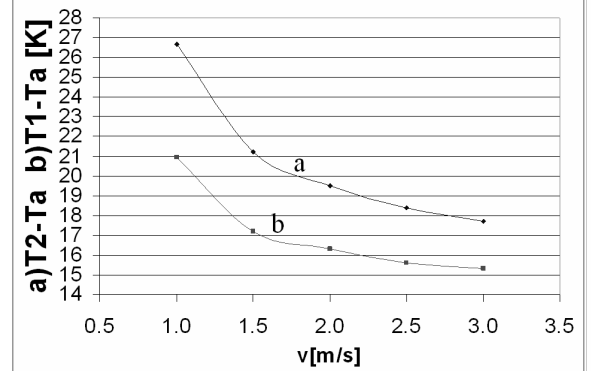

c)

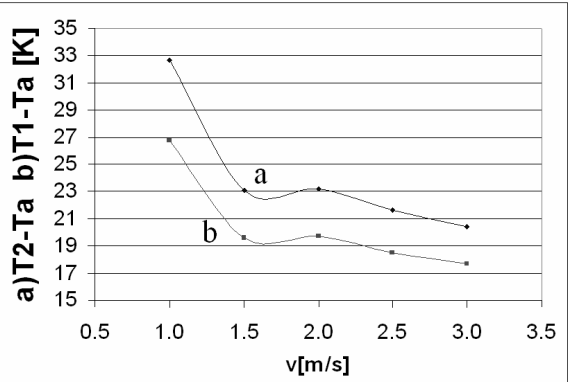

b)

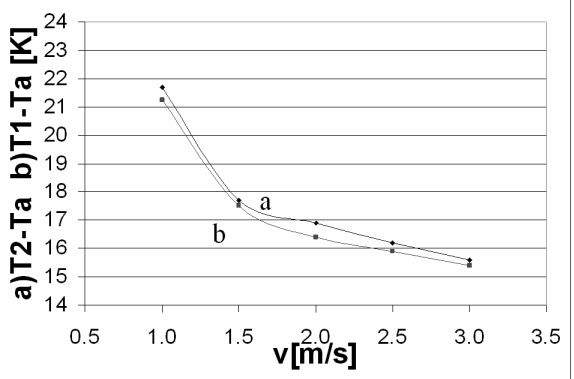

d)

Fig. 4. Functions $T 2-T a=f(v)$ and $T 1-T a=f(v)$ for the velocity range $1.0-$ $3.0 \mathrm{~m} / \mathrm{s}$ (simulations)

For configuration a) this disproportions are the largest. Air moving over simulated modules warms up what makes that downstream module has worse cooling conditions. From tested configurations the $d)$ one is the best. The disproportion between $T_{2}-T_{a}=f(v)$ and $T_{1}-T_{a}=f(v)$ values are the smallest and in practice they do not play important role.

For the b) configuration the best results are obtained for velocities from 1.0 to $1.5 \mathrm{~m} / \mathrm{s}$. For this range values of the functions: $T_{2}-T_{a}=f(\mathrm{v})$ and $T_{1}-T_{a}=f(\mathrm{v})$ rapidly decrease. Further increase of the velocity implies negligible results.

For configuration $c$ decrease of difference between function $T_{2}-T_{a}=f(v)$ and $T_{1}-T_{a}=f(v)$ values is visible only in $2.5-3.0 \mathrm{~m} / \mathrm{s}$ velocity range.

\section{Devices enhancing heat transfer - real model measurements}

There were performed tests of the real heat sources models in a wind tunnel. Two configurations were chosen for examination - with no extra elements enhancing heat transfer (a) and case with speed accelerator (d). They have the same dimensions as simulated ones. Substrate is made with poorly conducting material. Germanium window is mounted in the wind tunnel test section wall, what made possible temperature measurements with IR camera.

Functions values: $T_{2}-T_{a}=f(v)$ and $T_{1}-T_{a}=f(v)$ from measurements (Fig.5) take generally lower values than in simulations. It is due to the fact that in numerical 
simulations heat dissipation by radiation was not taken into account. The second reason is that insulation from the bottom of the real model was not ideal as in simulations and heat was also dissipated this way.

For the modules with no extra devices enhancing heat transfer dependencies $T_{2}-T_{a}=f(v)$ and $T_{1}-T_{a}=f(v)$ are practically linear. For the modules in configuration $d$ we observe that temperature differences $T_{1}-T_{a}$ and $T_{2}-T_{a}$ are generally lower than for configuration a. It is also visible that thermal wake phenomenon reversed. The source placed downstream $\left(P_{2}\right)$ has lower temperature than the upstream one $\left(P_{1}\right)$.

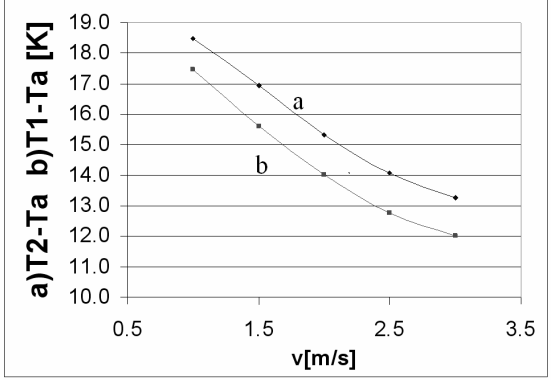

a)

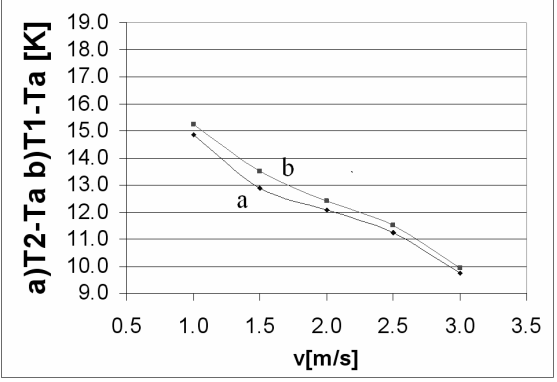

d)

Fig. 5: Functions $T 2-T a=f(v)$ and $T 1-T a=f(v)$ for the velocity range $1.0-$ $3.0 \mathrm{~m} / \mathrm{s}$, configuration a) and d), (measurements)

\section{Optimization of electronic devices placement on printed circuit board}

Problem considered in the second part of the work is to place optimally electronic devices on the PCB. They are convectively cooled with air stream with inlet velocity $U_{0}$. Components are placed at the bottom of a duct (Fig.6). There are eight electronic devices, all having different heat fluxes. There were made some simplifications of the model. It was assumed that electronic devices are flat. Model of a substrate does not include conduction. It is also assumed that air flow is laminar.

\section{Thermal solver and genetic algoritm}

Numerical engine for electronic devices placement optimization on the PCB includes genetic algorithm and thermal solver. Genetic algorithm searches arrangements that are checked by thermal solver if they satisfy requirements of the designer. Numerical simulations of heat dissipation are done in two dimensions.

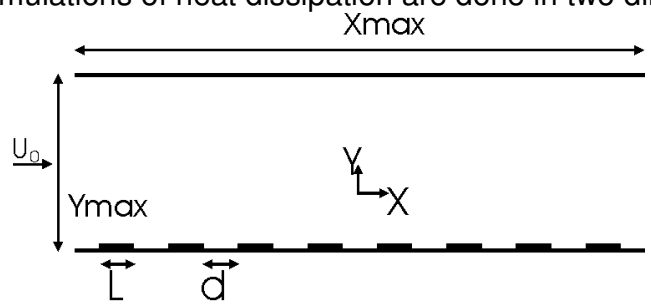

Fig. 6. Duct with electronic components

Numerical algorithm solves Navier-Stockes $(1,2)$ and Kirchhoff-Fourier (3) equations [3]. 


$$
\begin{aligned}
& \frac{\partial u}{\partial x}+\frac{\partial u}{\partial y}=0 \\
& u \frac{\partial u}{\partial x}+v \frac{\partial u}{\partial y}=-\frac{1}{\rho} \frac{\partial p}{\partial x}+v\left(\frac{\partial^{2} u}{\partial x^{2}}+\frac{\partial^{2} u}{\partial y^{2}}\right) \\
& u \frac{\partial T}{\partial x}+\mathrm{v} \frac{\partial T}{\partial y}=a \frac{\partial^{2} T}{\partial y^{2}}
\end{aligned}
$$

Equations (1-3) are solved using finite differences method [2] with the following boundary conditions:

$$
\begin{aligned}
& u(y=0)=0, \quad u\left(y=y_{\text {max }}\right)=0 \\
& \left.\frac{\partial u}{\partial x}\right|_{x=x \max }=0,\left.\quad u\right|_{x=0}=U_{0} \\
& \mathrm{v}=0, T_{a}=300 \mathrm{~K}
\end{aligned}
$$

where: $x, y$ - coordinates, $u$-velocity in $\mathrm{x}$ direction, $v$ - velocity in $y$ direction, $T$ - temperature, $T_{a}$ - ambient temperature, $v$ - kinematic viscosity, $a=\lambda / c p^{*} \rho(\lambda-$ thermal conductivity, $c p$ - specific heat, $\rho$ - density).

All simulations are done for inlet velocity $U_{0}=0.5 \mathrm{~m} / \mathrm{s}$ and very low Reylnolds number equal to 301 .

In the algorithm permutational coding is used which seems to be the best for this application. There are eight electronic devices. Their numbers create chromosome, for example: 52738461 . Each number is assigned to the heat source and their order denotes the place in the duct. At the beginning algorithm randomly chooses initial population of chromosomes.

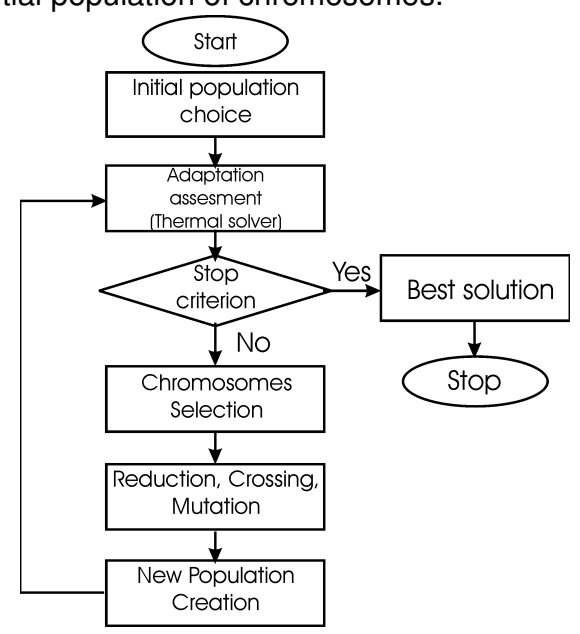

Fig. 7. Genetic algorithm block diagram

Using an objective function, adaptation assessment of chromosomes is done. In order to get the value of the objective function, thermal solver with optimality criteria are used. A few criterion are used: $T_{\max }$ (maximal temperature for all the devices), $T_{\text {mean }}$ (mean temperature of the devices) and weighted criterion $a \cdot T_{\max }+$ 
$b \cdot T_{\text {mean }}$ where $a, b$ are weights. As a stop condition, number of generations is used, which is equal to 100 .

Each generation consists of eight chromosomes. From this set two the best are selected and then they are crossed and mutated. After a new population is created algorithm is repeated [1] (Fig. 7).

\section{Results of optimal placement search}

From practical point of view it is beneficial that spaces between devices were not equal. In the paper two cases are considered. First - spaces are equal and algorithm only changes devices order. Second - algorithm searches optimal devices position and appropriate spaces between them.

\subsection{Equal spaces}

There are eight devices with different heat fluxes: 1:105, 2:300, 3:110, 4:500, $5: 115,6: 210,7: 120,8: 205 \mathrm{~W} / \mathrm{m}^{2}$ with length $l=0.005 \mathrm{~m}$ and spaces $d=0.005 \mathrm{~m}$ (Fig. 6). There is 8 ! (40320) possible orders of the devices. Solving this problem by calculating temperature distribution for all possible devices orders would be very time-consuming.

Simulated electronic devices are cooled with forced convection. This makes that temperature of each module depends on heat flux and temperature of the other devices placed upstream. For the simulations, a few criteria of optimality are chosen. It is one of the important issues to consider for proper work of the algorithm.

First used criterion of optimality is the highest temperature $T_{\max }$ among all devices - the aim is minimize it.

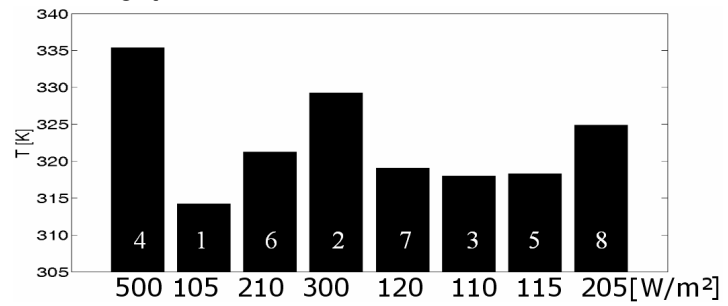

Fig. 8. Equal spaces, criterion $T_{\max }=335.35 \mathrm{~K}\left(T_{\text {mean }}=322.54\right)$

Fig. 8 presents exemplary results. They include devices order, heat flux that each device dissipates, maximal temperature appearing on the board $\left(T_{\max }\right)$, mean ( $\left.T_{\text {mean }}\right)$ and each device temperature. For the first criterion $\left(T_{\max }\right)$, the genetic algorithm always places module with the highest heat flux as the first in the duct. Fig.9 presents temperature distribution for the following devices order $\begin{array}{llllll}4 & 1 & 6 & 7 & 3\end{array}$ 58 as in Fig. 8. After the algorithm places module no. $4\left(500 \mathrm{~W} / \mathrm{m}^{2}\right)$ at the inlet, optimization ends because is not possible to obtain lower $T_{\max }$ for this device. This makes that algorithm is not able to improve order of other components because all the configurations with module $4\left(500 \mathrm{~W} / \mathrm{m}^{2}\right)$ at the inlet are equal for this criterion. For that reason second criterion of the lowest mean temperature $T_{\text {mean }}$ is considered. The aim is to obtain possibly uniform distribution of the temperature in the duct. 
http://dx.doi.org/10.21611/qirt.2006.094

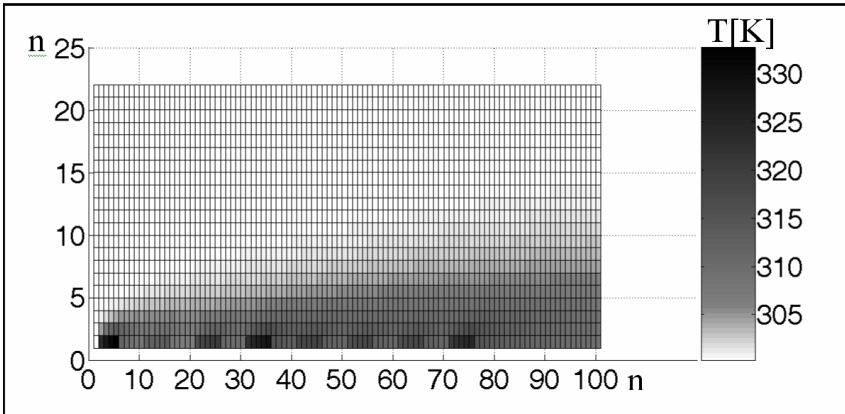

Fig. 9. Temperature distribution for devices order: $4 \begin{array}{llllll}4 & 6 & 7 & 3 & 8 & \text { (Fig. 8) }\end{array}$ (criterion - $T_{\text {max }}$ )

Results obtained for this criterion (Fig. 10) are slightly better than for the first one $\left(T_{\max }\right)$. Mean temperature is lower about $1 \mathrm{~K}$. Maximal temperature takes the same value. For all presented configurations device $4\left(500 \mathrm{~W} / \mathrm{m}^{2}\right)$ is at the inlet. The other devices are optimally placed considering the mean temperature of the entire structure. In this situation the device with the highest heat flux is the most effectively cooled.

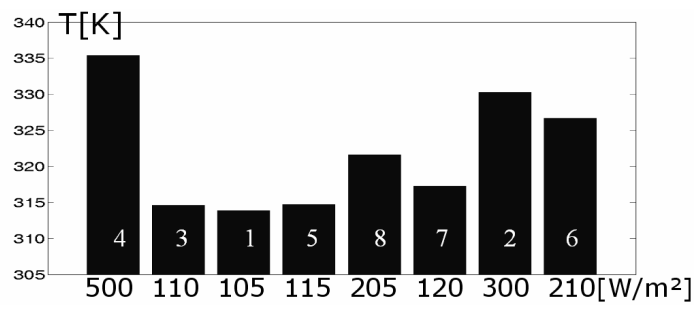

Fig. 10. Equal spaces, criterion $T_{\text {mean }}=321.77 \mathrm{~K}\left(\mathrm{~T}_{\max }=335.34 \mathrm{~K}\right)$

Third criterion includes both $T_{\max }$ and $T_{\text {mean. }} T_{\max }$ is considered as more important because each electronic module has a specific temperature which should not be exceeded. For this reason for $T_{\max }$ weight is equal to 10 while for $T_{\text {mean }}$ is equal to 1 . As it was expected the algorithm placed $4\left(500 \mathrm{~W} / \mathrm{m}^{2}\right)$ as the first one. Its temperature is equal to $335.35 \mathrm{~K}$.

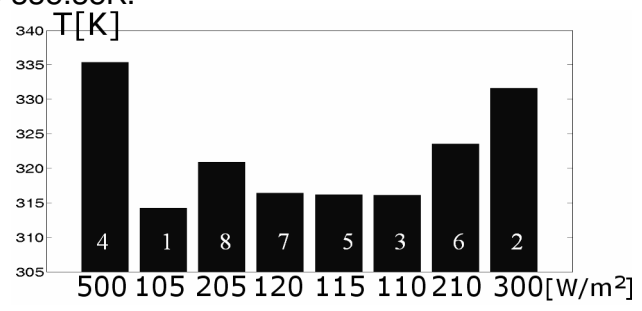

Fig. 11. Equal spaces, criterion, $a \cdot T_{\max }+b \cdot T_{\max }\left(T_{\max }=335.34 \mathrm{~K}\right.$,

$$
T_{\text {mean }}=321.78 \mathrm{~K} \text { ) }
$$

Modules with high heat flux are separated by modules with low heat flux what prevents hot spots occurrence. $T_{\max }$ is equal to $335.35 \mathrm{~K}$ and $T_{\text {mean }}$ is about $322 \mathrm{~K}$ (Fig. 11). 


\subsection{Variable spaces}

In the first attempt, spaces between electronic devices are equal, nevertheless they play important role in cooling. Therefore in the next step, the algorithm searches optimal devices order and optimal spaces between them. Algorithm varies the distance between the devices taking into account total length of the PCB equal to $0.088 \mathrm{~m}$. In this part of the work the same criteria of optimality ( $T_{\max }$, $\left.T_{\text {mean }} a \cdot T_{\text {max }}+b \cdot T_{\text {mean }}\right)$ are used as for the case with equal spaces between devices.

First criterion enables to control maximal temperature of the devices. Results (Fig. 12) are similar as for the case with equal spaces.

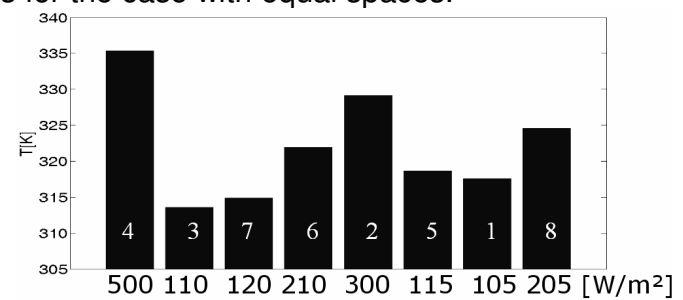

Fig. 12. Variable spaces, criterion $T_{\max }=335.34 \mathrm{~K}\left(T_{\text {mean }}=321.97 \mathrm{~K}\right)$

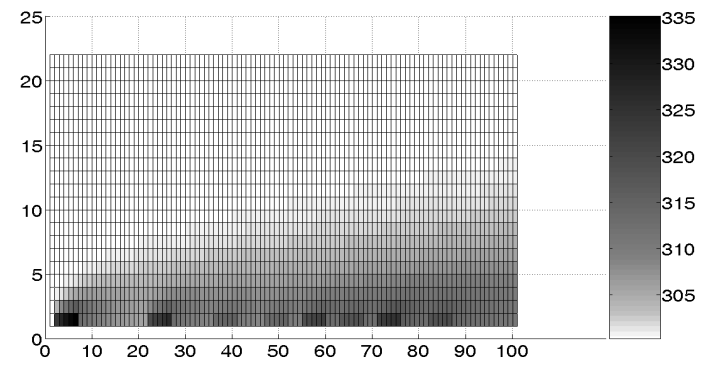

Fig. 13. Temperature distribution for Table 4 (criterion $-T_{\max }$ )

Dimensions of the spaces between devices are not presented in the bar graphs (Fig. 12,14,16). They are visible in the Fig. 13,15,17 that correspond to Fig. $12,14,16$ respectively. Results for the second (minimal $\mathrm{T}_{\text {mean }}$ ) criterion are presented in Fig. 14.

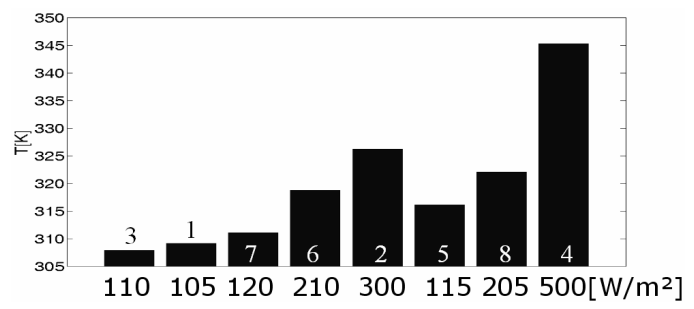

Fig. 14. Variable spaces, criterion $T_{\text {mean }}=319.54 \mathrm{~K}\left(\mathrm{~T}_{\max }=345.24 \mathrm{~K}\right)$

In this case the mean temperature of the devices is the lowest for all considered cases. It is even possible to obtain $T_{\text {mean }}$ equal to $319.54 \mathrm{~K}$. Nevertheless maximal devices temperature is not controlled and takes value equal to $345.24 \mathrm{~K}$ which is quite high. 
http://dx.doi.org/10.21611/qirt.2006.094

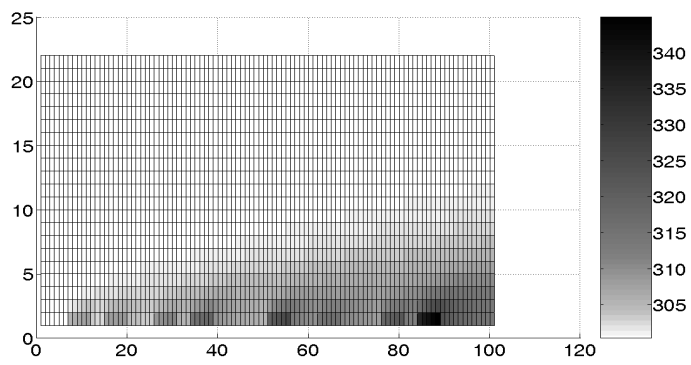

Fig. 15. Variable spaces, temperature distribution for criterion $-T_{\text {mean }}$

The last case with variable spaces between modules is for weighted criterion $a \cdot T_{\max }+b \cdot T_{\text {mean }}$. Weight equals to 10 and 1 respectively. It is assumed that the highest and mean temperature should influence order of the devices.

Fig. 16 present exemplary solutions obtained in this simulation. As it is visible in the Fig. 17 spaces between devices are not equal. In all presented configurations module no $4\left(500 \mathrm{~W} / \mathrm{m}^{2}\right)$ is placed as the first one at the inlet of the duct.

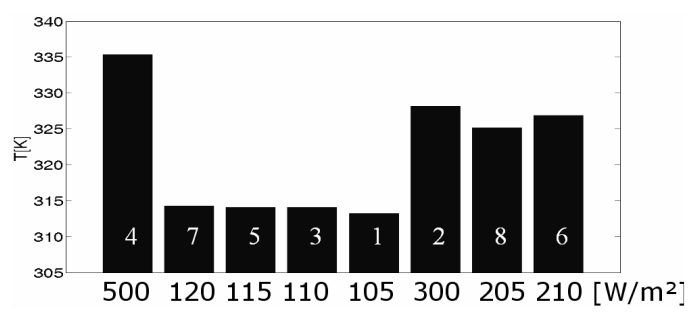

Fig. 16. Variable spaces, criterion, $a \cdot T_{\max }+b \cdot T_{\text {mean }}\left(T_{\text {mean }}=321.42 \mathrm{~K}\right.$, $T_{\max }=335.35 \mathrm{~K}$

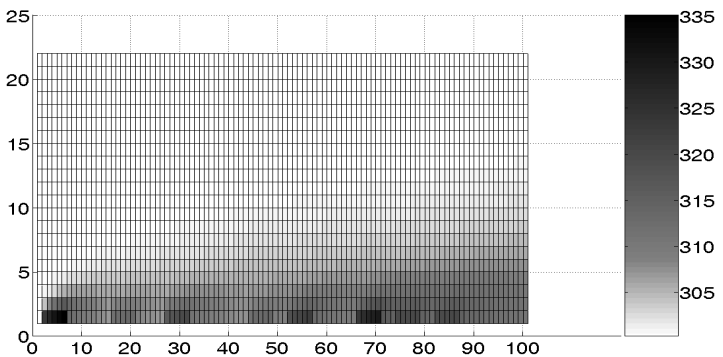

Fig. 17. Variable spaces, temperature distribution for $a \cdot T_{\max }+b \cdot T_{\text {mean }}$

This module has the largest heat flux and is the hottest. It strongly influences temperature of the other devices. This is the reason why numerical engine placed long distance after this module. Mean temperature is quite low (about $321 \mathrm{~K}$ ). 


\section{Conclusion} presented.

In the paper two ways of increasing heat transfer from electronic devices are

In the first one experiments and simulations confirmed that the thermal wake effect can play important role for electronic systems cooling. Differences of the upstream and downstream heat source temperature are visible. In general the larger velocity values are the stronger thermal wake effect is. For d) configuration cooling conditions for both sources are comparable. Despite the air warms up flowing over the first electronic device the second is even better cooled. It is because air velocity increase between elements enhancing heat transfer.

In the second part of the work simulations confirmed that optimization of the electronic devices placement is very important for long life-time their reliability. Genetic search occurred to be a promising tool for this purpose. Nevertheless, it is necessary to be very careful choosing criterion for the optimization. It turned out that $T_{\max }$ and $T_{\text {mean }}$ are not very good criteria. When $T_{\max }$ is minimized the algorithm do not optimizes position of all devices. Attention is only paid to the device with the highest heat flux. This remark concerns optimization with equal and variable spaces between modules.

When $T_{\text {mean }}$ is minimized with equal spaces similar results are obtained as for $T_{\max }$. Nevertheless in the case with variable spaces $T_{\text {mean }}$ is well minimized but $T_{\max }$ is unacceptable high.

It turned out that weighted criterion of $a \cdot T_{\max }$ and $b \cdot T_{\text {mean }}$ is quite good. It allows to control maximal temperature of the devices and also helps to minimize their mean temperature.

\section{REFERENCES}

[1] F. Herrera, "Genetic algorithms and soft computing", Physica-Verlag, pp. 51-68, April 1996

[2] E. Kącki, "Metody numeryczne dla inżynierów", A.C.G.M. LODART, pp. 133187, Decemver 1997

[3] B. Staniszewski, "Wymiana ciepła", Państwowe Wydawnictwo Naukowe, Warszawa 1980

[4] D. Dancer and M. Pecht, "Component placement optimization for convectively cooled electronic", IEEE Trans. Syst., Man, Cybern, vol. 18, pp. 199-205, 1989

[5] V. Queipo, J. A.C. Humphrey, A. Ortega, "Multiobjective optimal placement of convectively cooled electronic components on printed wiring boards", IEEE Transactions on Components, Packaging and Manufacturing Technology-Part A, Vol.21 NO. 1, March 1998

[6] S. J. Kim,S. W. Lee. Air cooling technology for electronic equipement. 1996 by CRC Press, Inc.

[7] A.K. da Silva, S. Lorente, A. Bejan. Optimal distribution of discrete heat sources on a plate with laminar forced convection, International Journal of Heat and Mass transfer 47 (2004) 2139-2148.

[8] B.A. Jubran, A.S. Al- Salaymech. Thermal wakes measurement in electronic modules in the presence of heat transfer enhancement devices, Applied Thermal Engineering 19 (1999) 1081-1096

[9] M. Felczak, B. Więcek; "Modelling and thermography measurements of thermal wake effect in electronic components" QIRT 2004 Belgia

[10] M. Felczak, B. Ostrowski, B. Więcek; „Zastosowanie tunelu powietrznego do badań konwekcyjnego odprowadzania ciepła z układów elektronicznych", Elektronika, Prace Naukowe, Wydział Elektrotechniki i Elektroniki PŁ 